\title{
Therapeutic Approaches in Locked-in Syndrome
}

\section{Soultana L. Papadopoulou ${ }^{1}$, Yannis Dionyssiotis ${ }^{1}$, Konstantinos Krikonis ${ }^{2}$, Nefeli Logopati ${ }^{3}$, Ivaylo Kamenov ${ }^{4}$, Sophia Markoula ${ }^{5}$}

\author{
${ }^{1}$ Department of Physical Medicine and Rehabilitation, University Hospital of Ioannina, Ioannina Greece \\ 2 Statistics and Research Design Company, DatAnalysis, Ioannina, Greece \\ ${ }^{3}$ Laboratory of Biological Chemistry, Medical School, University of loannina, loannina, Greece \\ ${ }^{4}$ Clinic of Orthopaedics \& Traumatology, Queen Giovanna University Hospital, Sofia, Bulgaria \\ ${ }^{5}$ Department of Neurology, University Hospital of loannina, loannina, Greece
}

\section{Correspondence:}

Yannis Dionyssiotis, Department of Physical Medicine and Rehabilitation, University Hospital of loannina, 45110, Greece

E-mail: dionyssiotis@gmail.com Tel: +30 2651099962

Received: 31 July 2018

Accepted: 23 Oct 2018

Published Online: 14 Nov 2018

Published: 30 Sep 2019

Key words: locked-in syndrome, individualized treatment, braincomputer interfaces (BCls), rehabilitation, communication improvement

Citation: Papadopoulou SL, Dionyssiotis Y, Krikonis K, Logopati N, Kamenov I, Markoula S. Therapeutic approaches in locked-in syndrome. Folia Med (Plovdiv) 2019;61(3):343-51.

doi: 10.3897/folmed.61.e39425
Locked-in syndrome (LIS) is a neuropsychological condition, in which patients present with quadriplegia, lower cranial nerve paralysis, and mutism. Diagnosis of LIS is difficult because of the similarities with other related syndromes, but it is of crucial importance to establish precise and early diagnosis in order to make the appropriate decisions according to the intervention and treatment planning. Access to a multidisciplinary, specialized team provides opportunity for continued improvement.

Individualized treatment improves long-term management. Assistive technology and advanced communication aids may help people with disabilities to regain more independence and take part in everyday life. Technological achievements, such as brain-computer interfaces (BCls) may potentially be of significant practical value to patients with LIS. Advancements in medical care, rehabilitation, and communication technology have focused on leading LIS patients to live meaningful lives in the society with the involvement of their families.

\section{INTRODUCTION}

Locked-in syndrome (LIS) is a rare neuropsychological condition, usually observed in inpatient rehabilitation after a severe stroke. LIS is characterized by preserved consciousness and cognitive functionality in parallel with lack of speech and complete paralysis, including cranial nerve pairs. ${ }^{1,2}$

The so-called locked-in syndrome was described in the medical literature for the first time in 1875 , by Darolles. ${ }^{3}$ The term LIS was first introduced by Plum and Posner in 1966 as a condition related to ventral pons lesion, disrupting both corticospinal and corticobulbar pathways, excluding the participation of the cortex. ${ }^{4,5}$ LIS is also known as "maladie de l'emmuré vivant', or 'cerebro-medullo-spinal disconnection'. ${ }^{6}$ Scientific and public awareness of LIS has significantly increased over the last 10 years. ${ }^{7}$
Despite the fact that consciousness is preserved, however, impaired attention, executive function, memory, and perception have been observed. ${ }^{7}$ These patients are able to communicate and express themselves, interacting with the environment, using only ocular movements and blinking, experiencing the unpleasant situation of paralytic mutism. ${ }^{8,9}$ People, suffering from this syndrome, face loss of all motor functions and high mortality rate. ${ }^{10}$

LIS typically occurs from a brainstem lesion, specifically in the ventral pons after basilar artery occlusion. ${ }^{11}$ Other reported causes include but are not limited to amyotrophic lateral sclerosis (ALS), tumors or abscesses, and postoperative complications. In any case, among the most frequent causes, are stroke and traumatic brain injury. ${ }^{12,13}$

Diagnostically, it is difficult to differentiate LIS 
from other pathological conditions with similar symptoms such as akinetic mutism (AM) and spinal cord injury (SCI) as there is not any standard approach for assessing such poorly responsive patients. ${ }^{14-17}$ The diagnosis is usually made approximately during the middle of the second month following onset. ${ }^{17}$ There are three distinct types of LIS: classic, incomplete and total, depending on the severity of the condition. ${ }^{16}$ An informative and functional diagnosis of LIS, in an ideal case, should allow not only to describe the present status of the patients but also to make a prognosis of the disease. ${ }^{17}$

One of the main perspectives of this study is to shed light on the importance of precise and early diagnosis of this condition. Another aim is to review data regarding to recent therapeutic approaches. Finally, it is of crucial importance to highlight the attempts and challenges, related to technological development of equipment and devices, used for optimizing the communication of these patients with their surroundings.

\section{CLASSIFICATION}

LIS can be divided into three types, depending on the extent of motor impairment. These types are classical LIS, partial LIS and total LIS. ${ }^{18,19}$ Classical LIS is characterized by anarthria, absolute immobility apart from vertical eye movements or blinking. Some minimal motor activity may be observed in patients with partial LIS. ${ }^{19}$ The other symptoms are the same as in the classical type. It is usually caused by a primary lesion to the brain stem, but a partial recovery is expected. ${ }^{20}$ Total LIS is the situation, characterized by loss of all mobility, including eye movements, while consciousness is preserved. ${ }^{18}$ According to American Congress of Rehabilitation Medicine (1995) LIS has five generalized characteristics, namely: (i) sustained eye opening, (ii) maintained basic cognitive abilities, (iii) aphonia or severe hypophonia (iv) quadriplegia and (v) vertical or lateral eye movement or blinking of the upper eyelid as the primary means of communication. ${ }^{3}$

\section{ETIOLOGY AND CLINICAL PRESENTATION}

The etiology of locked-in syndrome is multifactorial. ${ }^{20}$ One of the main causes of LIS is the existence of an infarct caused by an obstruction of the basilar artery. This situation is usually observed after left vertebral artery dissection secondary to a vertebral fracture at the $\mathrm{C} 6$ level..$^{21}$ It is related to ventral zone of the pons, with an implication of the cortico-spinal tract which finally produces acute tetraplegia. ${ }^{22}$ This pontine lesion has an impact on the long pathways running through the brainstem, and cranial nerves III and XII as well, while normally the reticular formation is preserved.$^{23}$ LIS is caused by hemorrhages, stroke and trauma. ${ }^{24-27}$ The etiology is acute in some cases, including brainstem stroke, which is the most frequent cause of LIS. In other cases, chronic factors, such as amyotrophic lateral sclerosis (ALS) lead to LIS. ${ }^{28}$ A serious brainstem lesion as a sequence of heart comorbidities, such as hypertension, atrial fibrillation and metallic cardiac valve replacement, can also provoke as sequence a LIS situation. Hypoglycaemia or hyperglycemia, or any disorders in glucose absorption are incriminated for LIS. ${ }^{29}$

A large proportion of patients with LIS suffer from decelerate posturing meaning the rigid extension of both the upper and lower limbs. This posturing may be either spontaneous or caused by painful stimuli. ${ }^{30}$ Furthermore, patients with LIS present with respiratory problems, with breathing insufficient. ${ }^{31}$ The lesion of the last pair of cranial nerves affects utterance, because of facial, tongue, and pharyngeal diplegia. As a result, severe difficulties in swallowing process and in producing speech are observed. All these disorders lead to alterations in the steering mechanisms of blood pressure and temperature. ${ }^{32}$

Patients suffering from LIS can communicate using only voluntary conjugated vertical movements of the eyeballs and blinking. ${ }^{6}$ This situation occurs since the supra-nuclear motor pathways travel caudally in the brainstem via Dejerine's bundle which lies dorsal to the main destructive lesion and remains unscathed. ${ }^{4}$

Fortunately, these movements are possible because of the partial preservation of cranial nerve $\mathrm{XI}$ and the mesencephalic reticular substance. ${ }^{33}$ The abnormality of eye movements is also usual, and this situation is widely known as "eye bobbing". The characteristics of the eye bobbing include a brisk deviation of the eyes in a downwards direction followed by a slow movement upward toward the resting position. ${ }^{6}$ Although LIS patients are conscious, attention, executive function, intellectual ability, perception as well as visual and verbal memory can be affected. ${ }^{31}$ Hearing is usually well preserved, but visual difficulties can arise from blurring, diplopia, and impaired accommodation. ${ }^{6}$ Other complications include vertigo, insomnia and emotional ability and pathologic laughter and crying (PLC). ${ }^{34}$ 
There are some difficulties in correlating clinical presentations to anatomical pathology. The specific characteristics of each patient, meaning age, baseline cognitive status and orientation, previous neurological disorders, and comorbidities, as well as the diversity in size and nature of the lesion itself contribute to these obstacles. During the acute care period, patients who are put under sedation, are seen for such brief time, so as it is difficult to make thorough clinical assessment. ${ }^{3}$

\section{DIAGNOSTIC TOOLS}

Recent literature supports a need for standardized diagnostic procedures to confirm LIS. Unfortunately, this is often reliant on imaging which may not show pathological findings even if other LIS symptoms are present. ${ }^{35,36}$ So, diagnosis of LIS is not usually made until approximately two months after onset. ${ }^{6}$ Experienced clinical doctors can use their knowledge of neuroanatomy and expected clinical presentations to isolate a suspected lesion location. Thus, they can aid in early diagnostics when imaging is not available. ${ }^{37}$ Since the cost of medical care is a key factor in the decisions of responsible health care providers, it is imperative that the morbidity and mortality of LIS be evaluated via a reliable diagnosis. $^{38}$

Clinical observation, CT of the brain, MRI, fMRI, PET, electroencephalogram, (EEG), electromyography (EMG), angiography are obligatory tests for accurate diagnosis. ${ }^{39,40} \mathrm{CT}$ criteria have linked drawings to compression of the basal cisterns and to lesions of the basal ganglia. ${ }^{41-43}$ MRI presents the highest sensitivity to lesions of the brainstem and the basal ganglia after traumatic brain injury (TBI). ${ }^{44-47}$ Hence, MRI might explain which cerebral lesions are related to LIS. ${ }^{48,49}$ Specialized programs, focused on identifying and differentiating purposeful and generalized responses to stimuli, are also used. ${ }^{47}$ The functional independence measure (FIM) allows capturing the patient's disability and how much assistance the patient requires to perform daily activities. ${ }^{3}$

The initial emphasis on patients suffering from LIS is on maintaining an airway and adequate oxygenation so early diagnosis is very important. Managing reversible medical causes and reducing risk factors are essential while preventing the complications of immobility, dysphagia, and incontinence. ${ }^{6}$

\section{THERAPEUTIC APPROACHES}

The brain uses these important channels, in order to communicate and control any changes in the external environment, to express thoughts and feelings. Patients are snagged in an unresponsive body, while consciousness is usually preserved. The quality of their life is poor. High levels of depression have been observed, because these patients are dependent on their caregivers and have difficulties participating in society. ${ }^{48}$ Quality of life in patients with LIS is associated with the recovery of verbal communication and the possibility of carrying out recreational activities with a true integration to the community life. ${ }^{2}$ There is currently no medical cure for LIS. Recent studies support the idea that the condition of LIS patients might be improved significantly, if there is a combination of pharmaceutical approach and physiotherapy. ${ }^{6}$

The basis for care of the person with LIS is threefold. The first need is to establish enough breathing, the second to give nutrition and the third to establish some means of communication. These patients face the problem of having a high risk of infections (pneumonia, urinary tract infections or pressure sores). So, it is important to measure the oxygen saturation in the blood. Positioning is important for breathing.

Advancements in medical care, rehabilitation, and communication technology have already enabled many chronic locked-in syndrome patients to become more sociable, based on the important support of family and friends. ${ }^{55}$ An interdisciplinary team in combination with immediate intervention, shortly after the manifestation of LIS, can help patients improve their condition and progress from complete LIS stage to incomplete LIS. ${ }^{49}$ The team includes physiatrists, neurologists, neuropsychologist, physical therapist, cognitive therapist, speech therapist, occupational therapist, and nurse. ${ }^{3}$ Chest physiotherapy, including deep breathing exercises, frequent positional changes, postural drainage, and suctioning, may limit pulmonary complications. Usually, corneal ulceration, due to impaired eye closure, can be treated by lateral tarsorrhaphy or botulinum therapy. Avoiding full eye closure is important because it will prevent communication. ${ }^{6}$ Occupational therapy (OT) is used by practitioners to improve the clinical condition of LIS patients, but it is of crucial importance the combination of OT with new technologies, to maximize the efficacy.

Treadmill therapy (TT) with body weight support is considered as a promising method in mobilizing LIS patients with severe motor deficits, in an upright walking position at a time when walking otherwise 
would be impossible. ${ }^{50}$ TT is based on the theory of activity dependent motor learning and adaptation of the central nervous system to an altered periphery. ${ }^{51}$ TT is usually applied as a supplement to the traditional training program with the intent to optimize the intensity of functional training. ${ }^{80}$ Video recording is obligated at the beginning and the end of the therapy period for each patient in order to evaluate their condition in a systematic manner. ${ }^{52}$

Repetitive sensor motor training (RST) has been developed to improve the outcome of motor rehabilitation of the centrally paretic arm and hand. Thus, in daily training sessions, patients are asked to perform isometric and isotonic contractions repetitively. Isometric contractions are to be executed as rapidly and as strongly as possible. Isotonic contractions must cover the entire range of motion that is actively available for the patient at a respective joint. In cases lacking active movement, the intended movements are repetitively carried out by an occupational therapist or physiotherapist. RST has been proven to improve functional motor capacity of the centrally paretic upper extremity and accelerate the time course of recovery significantly. ${ }^{19}$

Patients suffering from LIS rely on assistive technology to interact with the environment. Neurotechnological advances promise a lot to this direction. The target population of LIS patients is poorly characterized, as the precise number of patients in this condition is not well-defined and this situation makes research optimization difficult. ${ }^{53}$ There is an increasing need for communication-supporting technologies, leveraging the remaining senses of the patient along with physiological signals and improving the quality of patients' lives. Currently, a large variety of assistive technology (glasses, wheelchair, specially designed keyboards, etc.) for communication is available. ${ }^{54}$ The simplest communication codes present the alphabet arranged on a board, with the patient signaling the target letter by eye movements or any other available movement. When controlled head movements are present, the use of ultrasound or infrared head mouse systems can facilitate communication by formulating sentences using a letter board on a computer screen. ${ }^{55}$ If there are little movements, a single switch can be used in communication with a finger, shoulder, head or mouth. If only eye movements are preserved, the infrared eye-tracker system, based on infrared eye movement sensors, can be used ${ }^{56}$ by rehabilitation engineers and speech language therapists. Speechgenerating devices have also been used by LIS patients. They consist of an alphanumeric, phonetic or pictographic keyboard. ${ }^{2}$

The auditory steady-state response (ASSR) is an electro-physiologic response to auditory stimulation. It is amplitude-modulated by a specific frequency. 57,58 Mind concentration seems to modulate ASSR. Brain-computer interfaces can classify the selective attention of the patient. An auditory stimulation method is proposed to minimize auditory stress. It can be achieved by replacing the monotone carrier with familiar music and natural sounds for an ergonomic system. In particular, piano and violin melodies are usually employed in the music session. In the natural sound session, the sounds of water streaming and cicadas singing are normally used. ${ }^{59}$

Functional electric stimulation (FES), neuromuscular electrical stimulation (NMES), biofeedback, bioness, virtual reality, robotics, neuroprosthetics, robotic-assisted gait training (RAGT), tablet applications, as technological achievements, have recently become frequently used adjunctive treatment in inpatient rehabilitation. ${ }^{60-62}$ "Saebo package" is also very popular choice for rehabilitation. Saebo Flex is a mechanical, spring-loaded upper extremity thermoplastic orthotic which keeps neurologically flexed digits in an extended position so that persons with LIS can perform an active grasp with a spring-loaded assisted release. Saebo Stretch is a static positioning device for the forearm, which provides a prolonged static stretch to hypertonic wrist extensors. ${ }^{60}$ Specific computer applications are used routinely during treatment, to improve overall activity level, independence and communication. Interactive computer games have been shown to maximize motor, sensory, and cognitive skills in patients' rehabilitation. ${ }^{61,62}$

Augmentative and alternative communication (AAC) is a field of endeavor dedicated to providing effective interventions, to help patients whose natural speech is not functional, to be able to participate in their daily activities. The aim of the usual AAC interventions is to supplement or replace speech production, or both, with strategies and technology that offer characteristics of a natural language. Under condition, AACs give the opportunity to the patient with LIS of formulating sentences and saying anything at any time. ${ }^{63}$

Brain-Computer Interfaces (BCIs) or Neural Interface Systems (NISs) are augmentative communication devices that facilitate communication between the brain and an external machine using predominantly neuro electrical signals. ${ }^{64} \mathrm{BCIs}$ may 
overcome the problem of complete verbal isolation and motor inability ${ }^{65}$, to individuals with paralysis and anarthria resulting from neurological disorders such as LIS using brain activity to control external devices. So, it is a matter of urgency that there is a need for fast and reliable communication systems for individuals whose cognition and language capabilities remain intact although they are unable to control muscles of speech articulation or functionally use their limbs to control an assistive communication device.

BCIs allow patients with LIS, if they enroll to Brain Gate Neural Interface System pilot clinical trial (IDE), to find solutions and ways to communicate using neural point-and-click control. Technological advances and proliferation of mobile, tablet, and other touch-screen devices created a new field of increasing interest in Human-Computer Interaction, meaning the virtual (on-screen) keyboard design. Recent advanced specialized keyboards give the opportunity of a significant improvement in typing accuracy and speed, enabling typing rates over 10 correct characters per minute. ${ }^{66}$ Thus, the participant can use this interface to communicate face to face with research staff, by using text-to-speech conversion, and remotely using an internet chat application.

BCIs can be classified as invasive or noninvasive depending on the techniques utilized for controlling BCIs. The most common BCI category is based on electroencephalography (EEG-BCIs). ${ }^{67-69}$ Invasive and noninvasive $\mathrm{BCIs}$ enable detection of different types of brain signal. These systems have primarily been based on synchronous evoked potentials. ${ }^{70-72}$

The principles of all BCIs are quite similar. The detected brain signals are amplified; filtered and decoded using online classification algorithms. The classification of brain signals is created according to relevant characteristics. ${ }^{73}$ These signals are then filtered and smoothed before being fed back to users, thereby increasing the probability that they will reproduce this brain response. The output of the BCI can be used to control movement of a prosthesis, orthosis, wheelchair, robot or cursor or to direct electrical stimulation of muscles or the brain. ${ }^{74}$ The brain response can also be fed back as visual, auditory or haptic stimuli that vary in relation to the measured brain activity. ${ }^{75,76}$

Use of invasive BCIs requires surgical implantation of electrodes or multi-electrode grids in the $\mathrm{arm} / \mathrm{hand}$ area of the motor cortex of the patient, providing more information-rich control signals for BCIs. This type of BCIs measures activity patterns of neurons, which encode behaviorally relevant information. Rehabilitative BCIs are designed to facilitate recovery of neural function. Neuronal ensemble activity is recorded and digitized using specialized hardware and software.

Noninvasive BCIs require no surgical implantation and enable recording of brain signals from the external surface of the scalp. ${ }^{77}$ These interfaces can detect seven types of brain signal, namely slow cortical potentials, sensor motor rhythms, P300 event-related potential, steady-state visual evoked potentials, error-related negative evoked potentials, blood oxygenation level and cerebral oxygenation changes and can be recorded with EEG. Assistive BCIs are also designed to control external robotic devices, such as prosthetics. ${ }^{78-81}$

In parallel with EEG BCIs, BCIs based on functional magnetic resonance imaging (fMRI-BCIs) and BCIs based on near-infrared spectroscopy (NIRS-BCIs) are newly developed, promising for the learned regulation of emotional disorders and also disorders of young children. ${ }^{82,83}$

\section{CONCLUSION AND FUTURE PERSPECTIVES}

An important percentage of patients suffering from LIS pass away within a short time of diagnosis because of pulmonary complications such as respiratory muscle dysfunction, aspiration pneumonia, due to dysphagia, impaired cough or pulmonary embolism, as a consequence of lack of mobility. Early referral to a specialist rehabilitation service for specialist care and technology is therefore important, as after medical stabilization, life expectancy of these patients increases to several decades.

The use of technological advancements, such as BCIs to enable communication for patients who suffer from LIS is limited. Clinically applicable BCIs have only recently become available for patients with complete LIS. Invasive and noninvasive BCIs that use more than one type of brain signal have considerable potential, because no alternative exists for communication in LIS and no alternative to BCIs will exist in the foreseeable future. Despite the devastating neurological deficit in patients with LIS, combining the most modern technology and the slowly recovering mobility, some patients seem to be able to recover. Systematic assessment is needed, because of the possible consequences of moderate and selective cognitive disorders related to LIS, for communication and rehabilitation protocols. More research is still needed to improve and expand these methods and to adapt them to the patients. 


\section{REFERENCES}

1. McNair K, Lutjen M, Langhamer K, et al. Comprehensive, technology-based, team approach for a patient with locked-in syndrome: A case report of improved function and quality of life. Assist Technol 2017; 27: 1-6.

2. Lugo ZR, Bruno MA, Gosseries O, et al. Beyond the gaze: Communicating in chronic locked-in syndrome. Brain Inj 2015; 29(9): 1056-61.

3. Surdyke L, Fernandez J, Foster H, et al. Differential diagnosis and management of incomplete locked-in syndrome after traumatic brain injury. Case Rep Neurol Med 2017;2017:6167052.

4. Plum F, Posner JB. The diagnosis of stupor and coma. Philadelphia, Pa, USA: Davis Co; 1966.

5. Khanna K, Verma A, Richard B. "The locked-in syndrome": Can it be unlocked? J Clin Gerontol Geriatr 2011; 2: 96-9.

6. Leon-Carrion J, Van Eeckhout P, DominguezMorales MDR, et al. The locked-in syndrome: A syndrome looking for a therapy. Brain Inj 2002; 16(7): 555-69.

7. Garrard P, Bradshaw D, Jager HR, et al. Cognitive dysfunction after isolated brain stem insult. An underdiagnosed cause of long term morbidity. J Neurol Neurosurg Psychiatry 2002; 73: 191-4.

8. Kopsky DJ, Winninghoff Y, Winninghoff AC, et al. A novel spelling system for locked-in syndrome patients using only eye contact. Disabil Rehabil 2014; 36: 1723-7.

9. Chaudhary U, Birbaumer N, Ramos-Murguialday A. Brain-computer interfaces for communication and rehabilitation. Nat Rev Neurol 2016; 12(9): 513-25.

10. Casanova E, Lazzari RE, Lotta S, et al. Locked-in syndrome: improvement in the prognosis after an early intensive multidisciplinary rehabilitation. Arch Phys Med Rehabil 2003; 84(6): 862-7.

11. Nouh A, Remke J, Ruland S. Ischemic posterior circulation stroke: a review of anatomy, clinical presentations, diagnosis, and current management. Front Neurol 2014; 5: 30.

12. Haan J. Locked-in: The syndrome as depicted in literature. 2013; 206: 19-34.

13. Chang B, Morariu MA. Transient traumatic lockedin syndrome. Eur Neurol 1979; 18(6): 391-4.

14. Kohnen RF, Lavrijsen JCM, Bor JHJ, et al. The prevalence and characteristics of patients with classic locked-in syndrome in Dutch nursing homes. J Neurol 2013; 260: 1527-34.

15. Rao N, Costa JL. Recovery in non-vascular locked-in syndrome during treatment with Sinemet. Brain Inj 1989; 3(2): 207-11.

16. Bauer G, Gerstenbrand F, Rumpl E. Varieties of locked-in syndrome. J Neurol 1979; 221: 77-91.
17. Kotchoubey B, Lotze M. Instrumental methods in the diagnostics of locked-in syndrome. Restor Neurol Neurosci 2013; 31(1): 25-40.

18. Snoeys L, Vanhoof G, Manders E. Living with locked-in syndrome: an explorative study on health care situation, communication and quality of life. Disabil Rehabil 2013; 35: 713-8.

19. Hummelsheim H, Eickhof C. Repetitive sensorimotor training for arm and hand in a patient with lockedin syndrome. Scand J Rehab Med 1999; 31: 250-6.

20. Lukowicz M, Matuszak K, Talar A. A misdiagnosed patient: 16 years of locked-in syndrome, the influence of rehabilitation. Med Sci Monit 2010; 16(2): CS18-23.

21. Jang JW, Lee JK, Hur H, et al. Vertebral artery injury after cervical spine trauma: A prospective study using computed tomographic angiography. Surg Neurol Int 2011; 2: 39.

22. Sezer N, Akkuş S, Uğurlu FG. Chronic complications of spinal cord injury. World J Orthop 2015; 6(1): 24-33.

23. Landis BN, Leuchter I, San Millán Ruíz D, et al. Transient hemiageusia in cerebrovascular lateral pontine lesions. J Neurol Neurosurg Psychiatry 2006; 77(5): 680-3.

24. Doble JE, Haig AJ, Anderson C, et al. Impairment, activity, participation, life satisfaction, and survival in persons with locked-in syndrome for over a decade: follow-up on a previously reported cohort. $\mathrm{J}$ Head Trauma Rehabil 2003; 18: 435-44.

25. Raibagkar P, Chavali RV, Kaplan TB, et al. Reverse locked-in syndrome. Neurocrit Care 2017; 27: 108-14.

26. Schjolberg A, Sunnerhagen KS. Unlocking the locked in; a need for team approach in rehabilitation of survivors with locked-in syndrome. Acta Neurol Scand 2012; 125: 192-8.

27. Smith E, Regan M, Delargy M. Factors influencing discharge placement for locked-in syndrome survivors. Ir Med J 2008; 101(4): 112-6.

28. Lulé D, Zickler C, Häcker S, et al. Life can be worth living in locked-in syndrome. Prog Brain Res 2009; 177: $339-51$.

29. Negreiros dos Anjos M. "Locked in" syndrome following prolonged hypoglycemia. Diabetes Care 1984; 7: 613 .

30. Woischneck D, Skalej M, Firsching R, et al. Decerebrate posturing following traumatic brain injury: MRI findings and their diagnostic value. Clin Radiol 2015; 70(3): 278-85.

31. Smith E, Delargy M. Locked-in syndrome. BMJ 2005; 330(7488): 406-9.

32. Golubović V, Muhvić D, Golubović S, et al. Two different manifestations of locked-in syndrome. Coll Antropol 2013; 37(1): 313-6. 
33. Danilov Y, Kaczmarek K, Skinner K, et al. Cranial nerve noninvasive neuromodulation, new approach to neurorehabilitation. In: Kobeissy FH, editor. Brain Neurotrauma: Molecular, Neuropsychological, and Rehabilitation Aspects. Boca Raton (FL): CRC Press/Taylor \& Francis; 2015.

34. Sacco S, Sarà M, Pistoia F, et al. Management of pathologic laughter and crying in patients with locked-in syndrome: a report of 4 cases. Arch Phys Med Rehabil 2008; 89: 775-8.

35. Turner-Stokes L, Paul S, Williams H. Efficiency of specialist rehabilitation in reducing dependency and costs of continuing care for adults with complex acquired brain injuries. J Neurol Neurosurg Psychiatry 2006; 77: 634-9.

36. Rousseau MC, Pietra S, Nadji M, et al. Evaluation of quality of life in complete locked-in syndrome patients. J Palliat Med 2013; 16(11): 1455-8.

37. Carrai R, Grippo A, Fossi S, et al. Transient posttraumatic locked-in syndrome: A case report and a literature review. Neurophysiol Clin 2009; 39(2): 95-100.

38. Haig AJ, Katz RT, Sahgal V. Mortality and complications of the locked-in syndrome. Arch Phys Med Rehabil 1987; 68(1): 24-7.

39. Slazinski T, Johnson MC. Severe diffuse axonal injury in adults and children. J Neurosci Nurs 1994; 26: 151-4.

40. Sedney CL, Coger BR, Bailes JE. Posterior fossa subdural hematoma resulting in locked-in syndrome: case report. Neurosurgery 2011; 69: E497-500.

41. Marshall LF, Marshall SB, Klauber MR, et al. The diagnosis of head injury requires a classification based on computed axial tomography. J Neurotrauma 1992; 9(Suppl. 1): S287-92.

42. Sohn MK, Nam JH. Locked-in syndrome due to central pontine myelinolysis: case report. Ann Rehabil Med 2014; 38(5): 702-6.

43. Gayraud F, Martinie B, Bentot E, et al. Written production in a case of locked-in syndrome with bilateral corticopontic degeneration. Neuropsychol Rehabil 2015; 25(5): 780-97.

44. Tomycz ND, Holm MB, Horowitz MB, et al. Extensive brainstem ischemia on neuroimaging does not preclude meaningful recovery from locked-in syndrome: two cases of endovascularly managed basilar thrombosis. J Neuroimaging 2008; 18: 15-7.

45. Von Wild KRH. Functional neurorehabilitation in locked-in syndrome following $\mathrm{C} 0-\mathrm{C} 1$ decompression. Acta Neurochir 2005; 93: 169-75.

46. Woischneck D, Skalej M, Firsching R, et al. Decerebrate posturing following traumatic brain injury: MRI findings and their diagnostic value. Clin Radiol 2015; 70(3): 278-85.

47. Kearney S, McCann J, Hawkins S. Locked-in, walked out. Ulster Med J 2011; 80(3): 148-50.

48. Pistoia F, Cornia R, Conson M, et al. Disembodied mind: cortical changes following brainstem injury in patients with locked-in syndrome. Open Neuroimag J 2016; 10: 32-40.

49. Harms M. Inpatient management of Guillain-Barré syndrome. Neurohospitalist 2011; 1(2): 78-84.

50. Moseley AM, Stark A, Cameron ID, et al. Treadmill training and body weight support for walking after stroke. The Cochrane Database of Systematic Reviews. 4th ed., Hoboken: John Wiley \& Sons Ltd; 2005. pp. 1-43.

51. Wernig A, Muller S. Laufband therapy, the manual. Spinal cord damage, stroke, brain damage and MS, orthopedic disorders and others. Copyright. License Aku Med AS, Oslo; 2002. pp. 1-34.

52. Hoyer E, Normann B, Sorsdal R, et al. Rehabilitation including treadmill therapy for patients with incomplete locked-in syndrome after stroke; a case series study of motor recovery. Brain Injury 2010; 24(1): 34-45.

53. Pels EGM, Aarnoutse EJ, Ramsey NF, et al. Estimated prevalence of the target population for brain-computer interface neurotechnology in the Netherlands. Neurorehabil Neural Repair 2017; 31(7): 677-85.

54. Bacher D, Jarosiewicz B, Masse NY, et al. Neural point-and-click communication by a person with incomplete locked-in syndrome. Neurorehabil Neural Repair 2015; 29(5): 462-71.

55. Kopsky DJ, Winninghoff Y, Winninghoff AC, et al. A novel spelling system for locked-in syndrome patients using only eye contact. Disabil Rehabil 2014; 36: 1723-7.

56. Trojano L, Moretta P, Estraneo A, et al. Neuropsychologic assessment and cognitive rehabilitation in a patient with locked-in syndrome and left neglect. Arch Phys Med Rehabil 2010; 91(3): 498-502.

57. Kandogan T, Dalgic A. Reliability of auditory steady-state response (ASSR): comparing thresholds of auditory steady-state response (ASSR) with auditory brainstem response (ABR) in children with severe hearing loss. Indian J Otolaryngol Head Neck Surg 2013; 65(Suppl 3): 604-7.

58. Soderholm S, Meinander M, Alaranta H. Augmentative and alternative communication methods in locked-in syndrome. J Rehab Med 2001; 33: 235-9.

59. Heo J, Baek HJ, Hong S, et al. Music and natural sounds in an auditory steady-state response based brain-computer interface to increase user acceptance. Comput Biol Med 2017; 84: 45-52.

60. Doucet B. Neurorehabilitation: are we doing all that we can? Am J Occup Ther 2012; 66(4): 488-93.

61. Laffont I, Bakhti K, Coroian F, et al. Innovative technologies applied to sensorimotor rehabilitation after 
stroke. Ann Phys Rehabil Med 2014; 57: 543-51.

62. White J, Janssen H, Jordan L, et al. Tablet technology during stroke recovery: A survivor's perspective. Disabil Rehabil 2015; 37(13): 1186-92.

63. Hill K, Kovacs T, Shin S. Critical issues using braincomputer interfaces for augmentative and alternative communication. Arch Phys Med Rehabil 2015; 96(3 Suppl): S8-15.

64. Fried-Oken M, Mooney A, Peters B, et al. A clinical screening protocol for the RSVP keyboard braincomputer interface. Disabil Rehabil Assist Technol 2015; 10(1): 11-8.

65. Birbaumer N. Breaking the silence: brain-computer interfaces (BCI) for communication and motor control. Psychophysiology 2006; 43(6): 517-32.

66. Bacher D, Jarosiewicz B, Masse NY, et al. Neural point-and-click communication by a person with incomplete locked-in syndrome. Neurorehabil Neural Repair 2015; 29(5): 462-71.

67. Chaudhary U, Birbaumer N, Ramos-Murguialday A. Brain-computer interfaces for communication and rehabilitation. Nature Reviews Neurology 2016; 12: 513-25.

68. Holz EM, Botrel L, Kaufmann T, et al. Long-term independent brain-computer interface home use improves quality of life of a patient in the locked-in state: a case study. Arch Phys Med Rehabil 2015; 96(3 Suppl 1): S16-26.

69. Kjaer TW, Sørensen HB. A brain-computer interface to support functional recovery. Front Neurol Neurosci 2013; 32: 95-100.

70. Orhan U, Hild KE, Erdogmus D, et al. RSVP keyboard: an EEG based typing interface. Proc IEEE Int ConfAcoust Speech Signal Process; 2012. pp. 645-8.

71. Oken BS, Orhan U, Roark B, et al. Brain-computer interface with language model-electroencephalography fusion for locked-in syndrome. Neurorehabil Neural Repair 2013; 28(4): 387-94.

72. Acqualagna L, Blankertz B. Gaze-independent
BCI-spelling using rapid serial visual presentation (RSVP). Clin Neurophysiol 2013; 124(5): 901-8.

73. Gilja V, Pandarinath $\mathrm{C}$, Blabe $\mathrm{CH}$, et al. Clinical translation of a high performance neural prosthesis. Nat Med 2015; 21(10): 1142-5.

74. Donoghue JP, Nurmikko A, Black M, et al. Assistive technology and robotic control using motor cortex ensemble-based neural interface systems in humans with tetraplegia. J Physiol 2007; 579(Pt 3): 603-11.

75. Nijboer F, Furdea A, Gunst I, et al. An auditory brain-computer interface (BCI). J Neurosci Methods 2008; 167: 43-50.

76. Lugo ZR, Rodriguez J, Lechner A, et al. A vibrotactile p300-based brain-computer interface for consciousness detection and communication. Clin EEG Neurosci 2014; 45(1): 14-21.

77. Kübler A, Neumann N, Kaiser J, et al. Braincomputer communication: self regulation of slow cortical potentials for verbal communication. Arch Phys Med Rehabil 2001; 82: 1533-9.

78. Sellers EW, Vaughan TM, Wolpaw JR. A braincomputer interface for long-term independent home use. Amyotroph Lateral Scler 2010; 11: 449-55.

79. Zhu D, Bieger J, Molina GG, et al. A survey of stimulation methods used in SSVEP-based BCIs. Comput Intell Neurosci 2010, pp. 12.

80. Chavarriaga R, Millán J del R. Learning from EEG error-related potentials in noninvasive brain-computer interfaces. IEEE Trans Neural Syst Rehabil Eng 2010; 18(4): 381-8.

81. Yoo SS, Fairneny T, Chen NK, et al. Brain computer interface using fMRI: spatial navigation by thoughts. Neuroreport 2004; 15: 1591-5.

82. Patterson JR, Grabois M. Locked-in syndrome: a review of 139 cases. Stroke 1986; 17(4): 758-64.

83. Rousseaux M, Castelnot E, Rigaux P, et al. Evidence of persisting cognitive impairment in a case series of patients with locked-in syndrome. J Neurol Neurosurg Psychiatry 2009; 80: 166-70. 


\title{
Терапевтические подходы к синдрому деэфферентации
}

\section{Султана Л. Пападопулу' ${ }^{1}$, Янис Дионисиотис ${ }^{1}$, Константинос Криконис ${ }^{2}$, Нефели Лагопати ${ }^{3}$, Ивайло Каменов ${ }^{4}$, София Маркула ${ }^{5}$}

\author{
${ }^{1}$ Кафедра физикальной медицины и реабилитации, Университетская больница- Янина, Янина, Греция \\ ${ }^{2}$ Статистическая и исследовательская проектная компания ДатАналисис, Янина, Греция \\ ЗЛаборатория биохимии, Медицинский факультет, Университет Янины, Янина, Греция \\ ${ }^{4}$ Клиника ортопедии и травматологии, УМБАЛ „Царица Йоанна“, София, Болгария \\ ${ }^{5}$ Кафедра неврологии, Университетская больница- Янина, Янина, Греция
}

\begin{abstract}
Адрес для корреспонденции: Янис Дионисиотис, Кафедра физикальной медицины и реабилитации, Университетская больница- Янина, 45110, Греция E-mail:dionyssiotis@gmail.com Tel: +302651099962
\end{abstract}

Дата получения: 31 июля 2018 Дата приемки: 23 октября 2018 Дата онлайн публикации: 14 ноября 2018

Дата публикации: 30 сентября 2019

Ключевые слова: синдром деэфферентации, индивидуальное лечение, мозг-компьютерные интерфейсы (BCls), реабилитация, улучшение коммуникации

\section{Образец цитирования:}

Papadopoulou SL, Dionyssiotis Y, Krikonis K, Logopati N, Kamenov I, Markoula S. Therapeutic approaches in locked-in syndrome. Folia Med (Plovdiv) 2019;61(3):343-51.

doi: $10.3897 /$ folmed.61.e39425
Синдром деэфферентации (LIS) - это нейропсихологическое состояние, при котором у пациентов наблюдаются квадриплегия, паралич нижних черепных нервов и мутизм. Диагностика LIS затруднена из-за сходства с другими подобными синдромами, но крайне важно поставить точный и ранний диагноз, чтобы принять надлежащие меры относительно интервенций и плана лечения. Возможность обратиться к мультидисциплинарной, специализированной команде медицинских специалистов может привести к длительному улучшению состояния.

Индивидуальное лечение улучшает долгосрочное лечение заболевания. Вспомогательные технологии и современные средства коммуникации могут помочь людям с ограниченными возможностями обрести большую самостоятельность и участвовать в повседневной жизни. Технологические достижения, такие как мозг-компьютерные интерфейсы (BCls), могут иметь значительную практическую ценность для пациентов c LIS. Достижения в области медицинской помощи, реабилитации и коммуникационных технологий направлены на обеспечение полноценной общественной жизни для пациентов c LIS с участием их семей. 